\title{
CPR compression rotation every one minute versus two minutes: A randomized cross-over manikin study
}

\author{
Nutthapong Pechaksorn ${ }^{1}$ and Veerapong Vattanavanit ${ }^{1}$ \\ ${ }^{1}$ Prince of Songkla University Faculty of Medicine
}

April 28, 2020

\begin{abstract}
Background: Current basic life support guidelines recommend two-minute shifts for providing chest compressions when two rescuers are performing cardiopulmonary resuscitation. However, various studies have found that rescuer fatigue can occur within one minute, coupled with a decay in the quality of chest compressions. Our aim was to compare chest compression quality metrics and rescuer fatigue between alternating rescuers in performing one and two-minute chest compressions. Methods: This prospective randomized cross-over study was conducted at Songklanagarind hospital, Hat Yai, Songkhla, Thailand. We enrolled sixth-year medical students and residents and randomly grouped them into pairs to perform 8 minutes of chest compression, utilizing both the one-minute and two-minute scenarios on a manikin. The primary end-points were chest compression depth and rate. The secondary end-points included rescuers' fatigue, respiratory rate, and heart rate. Results: One-hundred and four participants were recruited. Compared with participants in the two-minute group, participants in the one-minute group had significantly higher mean (standard deviation, SD) compression depth [mm] (45.8 (7.2) vs $44.5(7.1)$, $\mathrm{P}=0.01)$ but there was no difference in the mean $(\mathrm{SD})$ rate [compressions per $\min$ ] (116.1 (12.5) vs $117.8(12.4), \mathrm{p}=0.08)$, respectively. The rescuers in the one-minute group had significantly less fatigue $(\mathrm{P}<0.001)$ and changes in respiratory rate $(\mathrm{P}<0.001)$, but there was no difference in the change of heart rate $(\mathrm{P}=0.59)$ between the two groups. Conclusion: There was significantly higher compression depth and lower rescuer fatigue in the 1-minute chest compression group compared with the 2-minute group. (Thai Clinical Trials Registry TCTR20170823001)
\end{abstract}

\section{Hosted file}

Manuscript 4_4_2020.doc available at https://authorea.com/users/309995/articles/440852-cpr-compressionrotation-every-one-minute-versus-two-minutes-a-randomized-cross-over-manikin-study

\section{Hosted file}

Table 4_4_2020.doc available at https://authorea.com/users/309995/articles/440852-cpr-compressionrotation-every-one-minute-versus-two-minutes-a-randomized-cross-over-manikin-study 

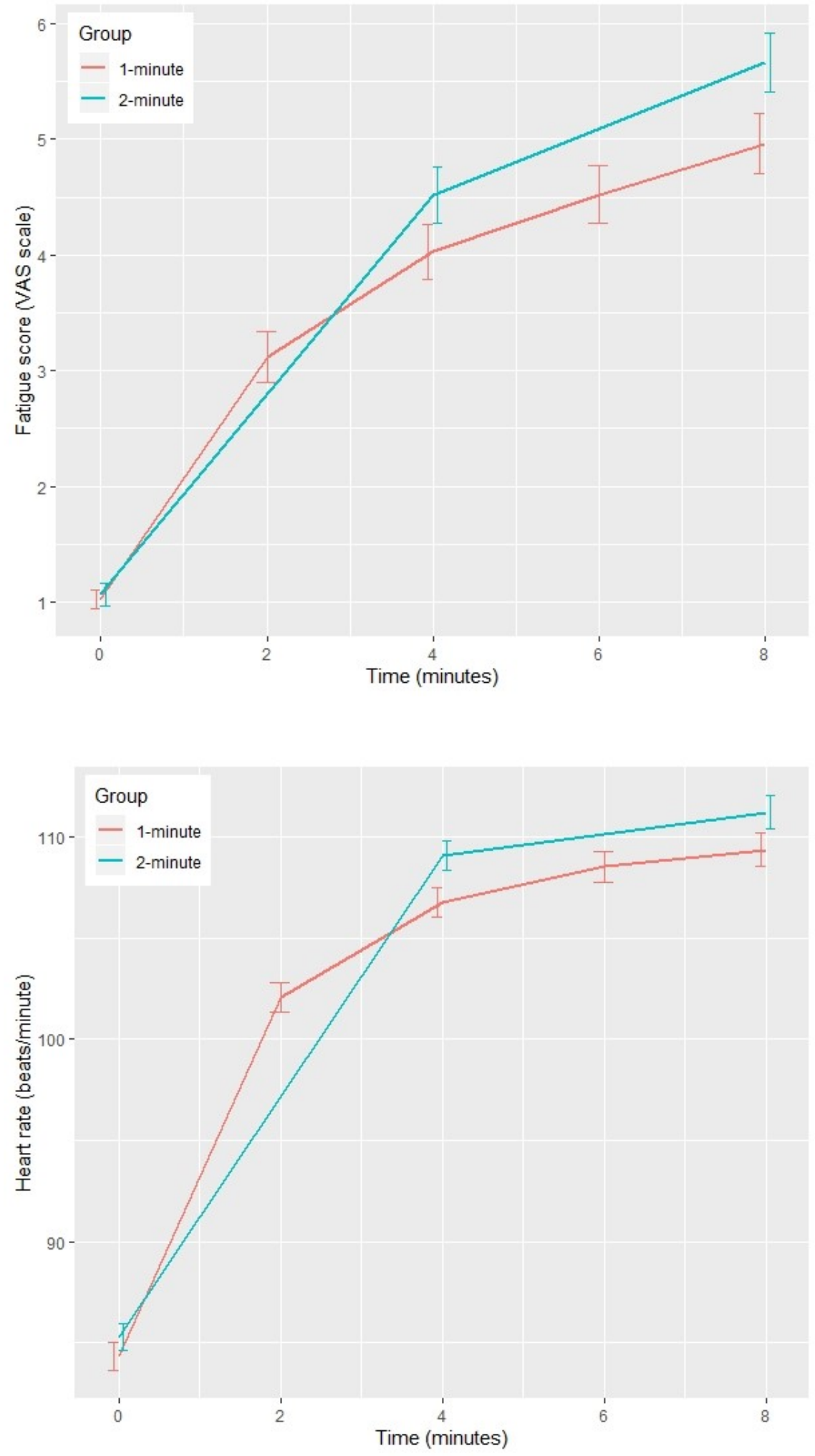


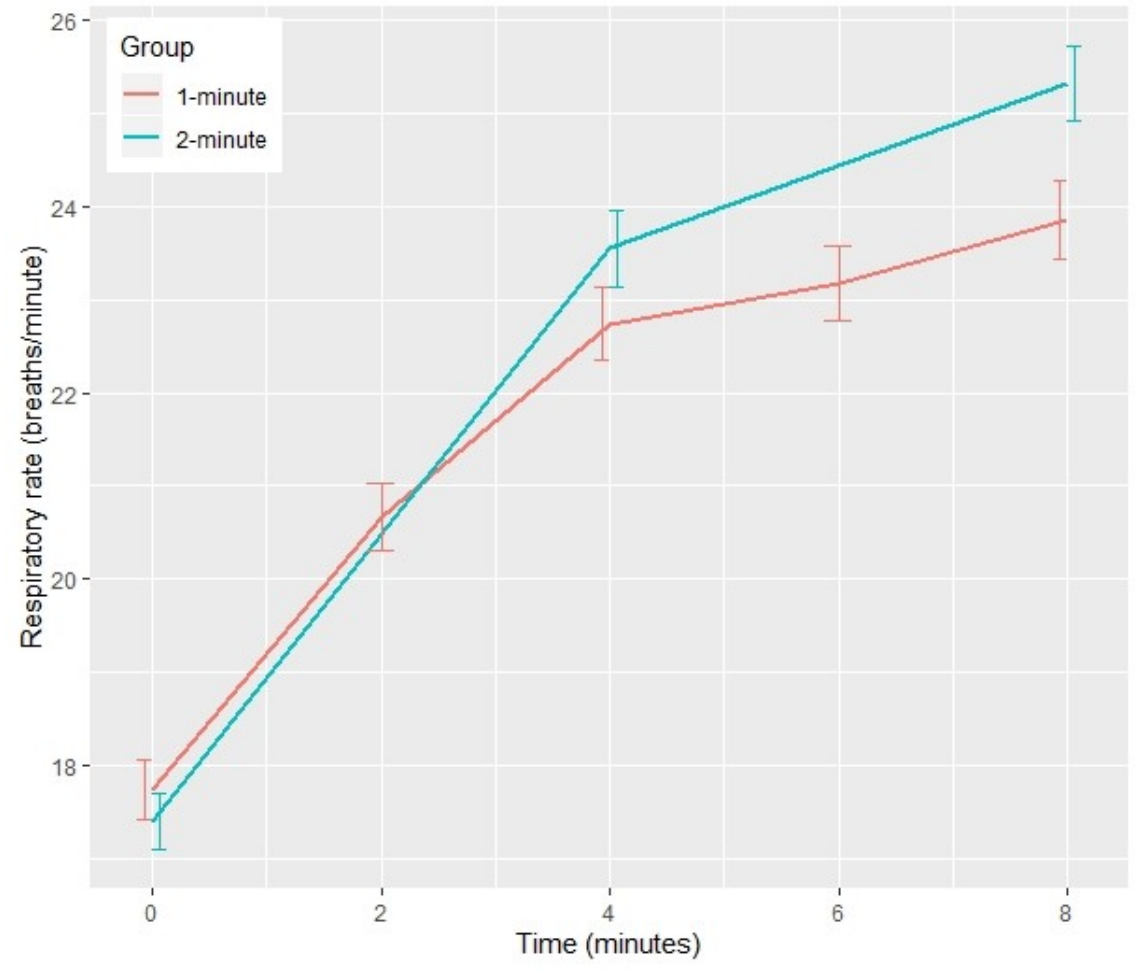

